\title{
AN INVESTIGATION OF THE USE OF SIMULATION TOOLS IN MANAGEMENT EDUCATION
}

Inas Ezz
School of Information Systems, Computing and Mathematics

Kingston Lane, Brunel University, Uxbridge UB8

$3 \mathrm{PH}$

Lampros Stergioulas

School of Information Systems, Computing and

Mathematics

Kingston Lane, Brunel University, Uxbridge UB8 3PH

\begin{abstract}
This paper investigates the use of simulation tools for business education, including Management School education and managerial training. The paper provides an overview of the need for non-traditional tools for learning, and the importance of simulation in learning. A particular focus is placed on the need for openness of these tools, aiming to promote their use and re-use. These needs were confirmed by the results of a brief study on simulation tools. An example of open simulation content provision is given by the OpenScout portal, which provides access to open educational resources in the area of management education and training. OpenScout offers a collection of resources from multiple sources located in different European countries. Initial experience from this initiative of collecting open simulation content demonstrated the limited availability of such type of resources.
\end{abstract}

\section{INTRODUCTION}

The aim of this paper is to investigate the importance and use of simulation tools in management education and training. As a result of this investigation, the benefits of such tools are reported, as well as the challenges involved in their use. The work of this paper has been extended to emphasize the importance of open content in this context. An example of open simulation content provision is given by the OpenScout portal, which provides access to open educational resources in the area of management education and training. OpenScout has collected resources from multiple sources located in different European countries. The first experiences in collecting open simulation content demonstrate the limited availability of these kinds of resources.

Before we introduce the issue of the use of simulation and gaming in education in general, and in the context of management education and training in particular, we will clarify what we mean by the terms simulation, gaming, and simulation gaming. Pasin and Giroux (2011) introduced the issue of simulation technologies by presenting Clark's (2009) work, in which he asserts that different authors use 


\section{Ezz, Loureiro-Koechlin, and Stergioulas}

different terminologies to define business simulation technologies that range from top management, flight simulators, business simulators, simulation games, macro-worlds/ micro-worlds to learning laboratories. The confusion between games and simulations seems to have always existed (Ellington et al. 1981; Lewis and Maylor, 2007). Although there have been many attempts to define these terms, it is still important to stress the differences between the two concepts, and to define a simulation game. Ellington et al. (1981), use the term game for "any contest (play) among adversaries (players) operating under constraints (rules) for an objective". Thus, a game is an opportunity to use one's skills and compete with others. The name also suggests a stimulating and enjoyable activity, even though in a pedagogical context games should not be used mainly for amusement; indeed, Abt (1970) refers to pedagogical games as serious games. A simulation is not necessarily a game. For instance, the simulations used by Holzinger et al. (2009) in their empirical study of medical education consisted of interactive animated virtual representations of complex physiological models. The students had no personal decisions to make but could, for example, visualize the impact of different values of pressure gradient, radius and bifurcations on arterial blood flow. In operations management research, simulations are also often used to anticipate the possible results of alternative designs or changes made to a complex system.

Games also commonly exist outside of simulated situations (for example, hopscotch, hockey, solitaire). Ellington et al. (1981) describe a simulation game as "an exercise that possesses the essential characteristics of both games (competition and rules) and simulations (ongoing representation of reallife)." Simulation games may be used for various purposes. Van der Zee and Slomp (2009) assert that they could help workers find solutions for specific problems, or to familiarize themselves with, and ease their acceptance of new work methods or systems. Wolfe (1993) explores their application in laboratory research, where they can be used to evaluate human reactions in particular situations (Pasin \& Giroux, 2011). Another perspective is explained by Larreche (1987). He sees games as tools that allow individuals to use and develop their decision-making skills in a fictitious competitive environment. Gaming has been an important and long tradition in the history of humans. From the earlier games of go and chess, to the relatively more recent monopoly, pacman and other electronic games, it has been an important activity for children and adults alike. This gaming approach has also been adopted to train people in a number of areas as diverse as politics, military, science, history, geography, languages, religion, or business. A major difference, however, is that the fictitious environment of an educational game has to be a faithful, albeit simplified, representation of the real world for the area of study.

In this paper, we shall use the term simulation, gaming, and simulation gaming interchangeably. This is supported by Larreche (1987), where he suggests that the educational game needs also to be a simulation, and the two words are often used interchangeably. Furthermore, the effectiveness of an educational game depends largely on the quality of the simulation in representing the behavior of the real world under study. As the main focus of this paper will be the use of such non-traditional tools in the context of business education, this paper provides an overview of the need for non-traditional tools for learning, and the importance of simulation in learning is provided in section 2. Section 3 provides examples of simulation and learning in Management Education. The Impact of Simulations on Education is discussed in section 4, while the case studies are presented in section 5. The paper concludes with a brief discussion and suggested next steps, which are presented in section 6.

\section{THE BENEFITS OF SIMULATION TOOLS IN DIFFERENT EDUCATIONAL FIELDS}

As the main aim of this paper is to investigate the importance and use of simulation tools in management education and training, this section highlights the benefits that accrue from the use of such non-traditional tools, as evidenced in the literature. This starts with a brief introduction of such benefits, followed by examples of such applications in different fields. 


\section{Ezz, Loureiro-Koechlin, and Stergioulas}

\subsection{Overview of Benefits}

Multiple benefits of the use of simulation tools have been addressed in the literature. For example, Qudrat-Ullah (2010) highlights the fact that the use of simulations for teaching and learning is becoming increasingly popular (Adobor and Daneshfar 2006; Moratiset al. 2006; Tao et al. 2009). Pasin and Giroux (2011) clarify that many students have spent much time playing computer games and are now very skilled at learning and applying complex sets of rules through game playing. Proserpio and Gioia (2007) add that the learning style of the new 'virtual generation' (V-gen) is very different from that of previous generations, as it is much more visual, interactive, and focused on problem-solving. While this could be seen as a threat to the traditional teaching style, which is based on verbal knowledge transfer and Socratic debates, it could also be seen as an opportunity to develop simulation games that build on V-gen skills and encourage the learning of management principles and practices. Simulation games are just one of many ways to acquire knowledge; we do not suggest that they can or should replace lectures, readings, case studies or other current learning methods. They have also been around for many years, long before personal computers were widely available. Nevertheless, now that a large proportion of students own powerful and interconnected laptops, it is easy to consider simulation games as an alternative to other types of problem-solving activities, one that can provide a complex and rich virtual environment conducive to deep learning. Initially applied mainly for training in the military and the aeronautics industry, simulation games are now used in the teaching of medicine, nursing, engineering, management, and several other fields. A growing body of literature describes new simulation games and measures their impact on student learning (Pasin and Giroux 2011).

Siddiqui et al. (2008) discuss these benefits in an extensive way. As they mention, simulationbased educational products are an excellent set of illustrative tools that proffer features like visualization of the dynamic behavior of a real system. Such products have a great efficacy in education, and are known to be among the top student-centered learning methodologies. These products allow students to practice skills such as critical thinking and decision-making. Simulation-based educational products are excellent "illustrative tools", used extensively in student centered learning methodologies. Such products provide an active learning technique, which stimulates a player's diverse cognitive skills and insight into a system by instantly staging the consequences of their actions and strategies. These actions and strategies can be tested without the apprehension of failures or reprisal. In addition, such products allow a player to increase his understanding of a system in a short time. Compared to real world experience, this accelerated learning is one of the unequaled advantages of such products. These simulation-based educational products provide a unique way to reinforce the theory discussed in the classrooms. As a player/ student becomes deeply involved in the scenario, simulation or gaming situation, a sense of competition and a desire to perform well is most likely to develop. Consequently, the teaching effectiveness of these products is exceptionally high. These products offer a great opportunity for the students to visualize and experience a practical scenario of what they learn in their coursework. Using Bloom's taxonomy, the first three levels of knowledge, comprehension, and application, in most cases, are fully supported. The fourth level of analysis could be present fully or partially depending upon the type of the tool or product and its use by the instructor.

\subsection{Examples of Simulation-based Education in Different Fields}

Multiple research efforts have reported the use of simulation in learning in the context of different fields. Siddiqui et al. (2008) reported a few examples such as the Shifrony and Ginat (1997) study, where a simulation game is developed for teaching communication protocols. The students act as protocol components in this game. It is reported that this method has significantly improved the level of understanding and motivation among students. Furthermore, Ponce (2001) developed an educational tool 


\section{Ezz, Loureiro-Koechlin, and Stergioulas}

for the analysis of some parameters in wireless communication. This tool is especially interesting for telecommunications students, since it provides an easy way to understand the characterization of radio channels. The graphical visualization of the results allows students to identify the path followed by each ray, from its origin at the transmitter antenna to the receiver after reflection, diffraction, etc. It also allows students to see its contribution to path loss, the power delay profile, and the direction of arrival. Another example is Hantsaridou et al. (2005), where a multimedia module for climate-simulation-experiments is presented. The application was based on the energy balance model. The proposed method was free from numerical or algebraic computations. To motivate the students into learning, the fundamental principles of the subject are taught in an active learning environment. Recent research such as Wonga et al. (2011) add that a variety of studies in the field of MCSCL (Mobile Computer supported Collaborative Learning) has explored opportunities for designing learning applications through networked mobile technologies (e.g., Liu and Kao, 2007; Looi et al., in press; Yinet al., 2007; Zurita and Nussbaum, 2004). While such innovations coupled with learning design look promising, we need to deal with the challenge of adoption by teachers in real classrooms.

One of the application fields that have attracted the attention of researchers since the early $1960 \mathrm{~s}$ is management education (Wells 1993), which will be discussed in the next section as it is the primary focus of this research.

\section{SIMULATIONS AND LEARNING IN MANAGEMENT EDUCATION}

As mentioned above, the aim of this paper is to investigate the use of simulation tools in the context of management education. Thus, this section provides an overview of the use of such tools, followed by the discussion of the nature of simulations in management education.

\subsection{Overview}

The origins of gaming and simulation in general, and in business education in particular, have been discussed by several researchers, including Larreche (1987) and Pasin and Giroux (2011). Pasin and Giroux (2011) present multiple research efforts in this context. Wells (1993) traces management simulations back to the 1950s, when ex-military managers transferred the experience they had acquired with war games. The Top Management Decision Simulation was developed in 1956 by the American Management Association (AMA) and by 1961, more than 100 business games had been published in the U.S. alone, and more than 30,000 executives had played them (Wells, 1993). Larreche (1987) also mentions that The American Management Association produced the Top Management Simulation in 1957 and Andlinger published a description of his manually rated business game in 1958. In 1962, the first survey of marketing games was published in the Journal of Marketing. It was in the early 1960s that some business games, such as the Carnegie Tech Management Game and INTOP became widely available. By 1968, virtually all business schools were using at least some form of game in their teaching programs. By 1970, it was estimated that over 200 games were in existence and over 100,000 executives had been exposed to them. Cullingford et al. (1979) add that in the 1970s, management games based on computer simulations passed through the stage of acclaim and disillusionment to take up a significant but fairly minor place in the array of modern teaching techniques (Pasin and Giroux, 2011).

Fifteen years later, however, Lane (1995) asserted that "management games and simulations are in the news," and that their use was increasing. This assertion was confirmed by a 1998 survey that showed that more than $60 \%$ of American businesses with more than 500 employees used simulations games in their training activities (Faria 1998). In 2004, Faria and Wellington conducted another survey of business school professors in North America and found that more than $30 \%$ of the 1085 respondents used business simulations (Faria and Wellington, 2004). In the last ten years alone, new simulation games were developed to teach marketing (Shapiro 2003), financial management (Bruce 2008; Uhles et al. 2008), 


\section{Ezz, Loureiro-Koechlin, and Stergioulas}

project management (Vanhoucke et al. 2005), knowledge management (Chua 2005), risk management (Barrese et al. 2003) and microeconomics (Gold \& Gold 2010). According to Faria et al. (2009), management simulation games belong to one of three types: top management games (i.e. games including all aspects of an organization and usually involving strategic decisions), functional games (i.e. simulation games focusing on a specific area of business), and concept simulations (i.e. a simulation concentrating on a specific type of decision) (Pasin and Giroux 2011). Specifically, computer simulation-based interactive learning environments (ILEs) are often developed and used to improve people's decisionmaking in the context of the dynamic complexity of business settings by facilitating user learning (Qudrat-Ullah and Karakul 2007; Romme 2003).

\subsection{The Nature of Simulations in Management Education}

According to Mahboubian (2010), simulations in the context of management education are generally used to help people understand the dynamics behind the choices that people make when running a business. These choices are made in a variety of areas within the management field. Some of these choices can be very life-like and complex; while others may be as simple as a tutorial that uses simple math to teach basic business skills (e.g., how to perform an inventory). The better ones use complex algorithms and include virtual characters with life-like back-and-forth conversation that challenge learners to understand how decisions can affect a large organization's success or failure. Siddiqui et al. (2008) provide some examples of simulations in the context of management education, which show that these efforts have been addressed since the 1980s, and in different areas within management. For example, in Avolio (1988) a simulation game, conducted on transformational and transactional leadership, is presented. In addition, a financial accounting and investment simulation game is developed and studied in a classroom environment in Albrecht (1995). The application of an industry simulation game in a business course $\mathrm{f}$ study is discussed in Margaret (1995). It is concluded that industry simulation is a potentially useful tool for in-house training programs. Curland and Fawcett (2001) examine the perceived problems with numerical skills applied to subject areas such as operations management and finance using simulation games. Furthermore Khaled (2001) presents an equipment-replacement game to aid in teaching and explaining the different effects of the strategies of buying/selling of equipment on the various economic performances of the construction companies. Santos (2002) developed an Internet-based interactive teaching aid that introduces students to the domestic and international consequences of the monetary policies of different nations. This game differs from other simulators in that it allows students, who represent nations, to interact with each other, rather than with a computer.

One of the management areas in which the use of simulation is wide spread is supply chain management. For example, Alarcon and Ashely (1999) present a simulation game to test various lean production strategies and their impact on project's cost and scheduling. Anderson and Morrice (2000) describe an implementation and development of a java-based, multiplayer, multigroup, and distributed simulation game based on the classical beer game. Further, in Anderson and Morrice (2000) a simulation game is proposed that is designed to teach service-oriented supply chain management principles and to test whether managers can use them effectively. A modified beer game is presented in Sparling (2002). Beer game is one of the most popular games in supply chain education that has introduced the problem. In Sparling (2002), the game is taken to the next level by helping students or managers to plan effectively ahead, to overcome these problems and manage an efficient supply chain. Holweg and Bicheno (2002) describe how a participative simulation model is used to demonstrate supply chain dynamics and to model possible improvements to an entire supply chain. Chua (2005) bridged the gap between the gaming and simulation community and the knowledge management community. He provided a template for designing and implementing knowledge management simulation game. He also used this template to show the viability and the effectiveness of a simulation game. Siddiqui et al. (2008) also provide an example of a supply chain simulator that tries to emulate an international supply chain network. This supply chain is 
used to deliver goods such as electronic equipment or a machine. The performance of these supply chains is judged by parameters such as inventory holding cost, backorder cost, and transportation cost, etc.

\section{THE IMPACT OF SIMULATIONS ON EDUCATION}

\subsection{Overview}

Considering the costs of developing and managing simulation games in terms of both time and money, it is only natural to question whether simulation games are really worth the effort. Indeed, most research articles on the topic provide some measure of their effectiveness. For example, Salas et al. (2009) created the following categories of training outcomes: Reactions (how learners subjectively react to the training strategy), learning (how much has been learned using this strategy), behavior (how competent learners have become), and results (the extent to which learners perform better in real life and attain superior results). Whereas the first two training outcomes can be measured immediately after the training activity, the last two outcomes can be assessed only on the job, well after the training has finished.

According to Pasin and Giroux (2011), most studies of management simulation games evaluate learners' reactions to the new learning tool, a conclusion similar to that reached by Gosen and Washbush (2004) in their review of the literature on experiential learning assessment. Attempts to measure other types of outcome are less common, particularly when simulation games are used for teaching management. Several recent examples of research measuring cognitive-based outcomes in medicine and nursing education have been found, e.g., Ackermann (2009), Cherry et al. (2007) and Nguyen et al. (2009). However, they do not measure the impacts of simulation games; they measure the learning outcomes of high-fidelity simulations (for instance, performing reanimation techniques on electronic mannequins simulating human patients). Some of these impacts are presented in the table below:

Table 1: Examples of research measuring various outcomes of a simulation game (Pasin \& Giroux, 2011, p.1243).

\begin{tabular}{|l|l|l|l|l|}
\hline Type of outcome & $\begin{array}{l}\text { Type of } \\
\text { learning } \\
\text { outcome }\end{array}$ & Authors & Type of research & Results \\
\hline $\begin{array}{l}\text { Reaction and } \\
\text { learning } \\
\text { outcomes }\end{array}$ & Skill-based & $\begin{array}{l}\text { Léger } \\
(2006)\end{array}$ & $\begin{array}{l}\text { Measured two types of outcomes } \\
\text { of an ERP simulation game; } \\
\text { MBA and business } \\
\text { administration undergraduate } \\
\text { students }(n=35) ; \text { perceived } \\
\text { learning questionnaire and } \\
\text { standard post-course evaluation } \\
\text { form; progression of financial } \\
\text { results for several runs of the } \\
\text { simulation game, SAP } \\
\text { certification success rate of } \\
\text { participants. }\end{array}$ & $\begin{array}{l}\text { Students' performance } \\
\text { improved during the game. } \\
\text { 93\% of the students received } \\
\text { their SAP certification. } \\
\text { Students were enthusiastic } \\
\text { about their experience. After } \\
\text { the simulation was } \\
\text { implemented, both courses } \\
\text { ranked in the first quintile of } \\
\text { all the courses offered in the } \\
\text { business school. }\end{array}$ \\
\cline { 3 - 5 } & & Weiss \\
& (2008) & $\begin{array}{l}\text { Measured two types of outcomes } \\
\text { of an international business } \\
\text { negotiation simulation game; } \\
\text { MBA and business }\end{array}$ & $\begin{array}{l}\text { Students and instructor } \\
\text { perceived that students had } \\
\text { improved a wide set of basic } \\
\text { and complex international }\end{array}$ \\
\hline
\end{tabular}




\begin{tabular}{|c|c|c|c|c|}
\hline Type of outcome & $\begin{array}{l}\text { Type of } \\
\text { learning } \\
\text { outcome }\end{array}$ & Authors & Type of research & Results \\
\hline & & & $\begin{array}{l}\text { administration undergraduate } \\
\text { students (not specified); post- } \\
\text { game student report, standard } \\
\text { post-course evaluation form, pre- } \\
\text { game and post-game evaluations } \\
\text { by instructor. }\end{array}$ & $\begin{array}{l}\text { business negotiation skills. } \\
\text { Students have rated the } \\
\text { dimension "learned a great } \\
\text { deal" at a modal score of } 7 / 7 \\
\text { in each of the last } 10 \text { years. }\end{array}$ \\
\hline & $\begin{array}{l}\text { Cognitive- } \\
\text { based }\end{array}$ & $\begin{array}{l}\text { Mitchell } \\
\text { (2004) }\end{array}$ & $\begin{array}{l}\text { Compared two teaching methods, } \\
\text { simulation game plus some case } \\
\text { studies ( } n=64) \text { and only case } \\
\text { studies }(n=66) \text { using two types } \\
\text { of outcomes; business } \\
\text { administration undergraduate } \\
\text { students; perceived learning } \\
\text { questionnaire with closed } \\
\text { questions, post-game exam. }\end{array}$ & $\begin{array}{l}\text { No significant difference for } \\
\text { any of the outcome measures. } \\
\text { However, when asked "What } \\
\text { is your recommendation } \\
\text { regarding using this simulation } \\
\text { in the next course?" } 77 \% \text { of } \\
\text { the students who participated } \\
\text { in the simulation answered } \\
\text { "definitely yes" and } 18 \% \\
\text { "somewhat yes." }\end{array}$ \\
\hline
\end{tabular}

\subsection{Motivation and Engagement}

According to Tao et al. (2009), there is a close relationship between educational simulation games and learning in the existing literature. Randel et al. (1992) discovered that educational simulation games can increase the motivation to learn. Terrell and Rendulic (1996) specifically indicated that games increase the students' internal motivation as well as their learning performances. Interestingly, Prensky (2003) pointed out that, from the perspective of successful learning, motivation is an indispensable condition and games just happen to provide such a condition. In their experiment, Schwabe and Göth (2005) applied games in their learning activities, which not only increase the motivation of the students but also increase the opportunity for them to interact with each other. Mahboubian (2010) states that some simulations provide a safe environment in which to make mistakes and allow learning to take place without pulling expensive equipment offline. This is also supported by Adobor and Daneshfar (2006) and Salas et al., (2009).

Pasin and Giroux (2011) add that simulation games are more engaging and motivating than other teaching strategies (Salas et al., 2009). In addition to providing an enhanced learning experience, simulation games allow participants to learn complex skills in what can be characterized as an enhanced reality. Further, the absence of real risk allows participants to increase their confidence level in a less stressful but still stimulating environment (Alinier 2003). In addition, simulation games can present situations that rarely occur in real-life yet require specific and critical skills (Baker et al. 2005; Salas et al. 2009). In the same vein, they allow for multiple repetitions of similar situations, thus accelerating learning (Baker et al., 2005; Salas et al., 2009). Furthermore, in contrast to real life, it is possible to stop the simulation game and take time to reflect, or do a partial re-run to evaluate the effects of alternative decisions (Cousens et al. 2009). Also, participants can also quickly get clear and meaningful feedback on their actions, which is rarely possible in real-life (Faria and Dickinson 1994). Finally, overly complex situations can be simplified and made more manageable (Cook \& Swift 2006). 


\section{Ezz, Loureiro-Koechlin, and Stergioulas}

Despite the benefits we discussed above, an important issue is the relatively high cost of simulation, which is one of the main challenges in its adoption (Pasin and Giroux 2011). Thus, the next section is going to investigate the use of simulation tools in the context of management education, the views on how simulations can enhance skill development, and the achievement of learning objectives, together with the challenges for such adoption including cost. Overcoming the cost challenge through the use of open content is one of the aims of OpenScout objectives, as we will see in the following section.

\section{CASE STUDY}

The research method employed in this work is case study research. This has been performed in two phases - the first aims to understand the views of simulation in management education through multiple stakeholders within embedded case studies using semi-structured interviews (based on previous literature in this context); while the second phase focuses on the implementation of open-simulation provision to overcome some of the barriers that have been reported in the first phase. The analysis of the first phase was performed through pattern matching. The technique for gathering facts was mainly semi-structured interviews.

\subsection{Views on the Use of Simulation in Management Education}

In early 2011 a Simulation Tools study was undertaken in the School of Information Systems, Computing and Mathematics, University of Brunel. This study examined the opinions of (mainly) academic staff about their use of simulations in teaching or training. It also included questions about their views on how simulations can enhance skill development, and the achievement of learning objectives. Interviews were carried out face-to-face or via video conferencing (using Skype) with 23 respondents from Universities in the UK, Australia, Norway and Egypt. Interviewees were selected because of their (past and/or present) interest in simulations and use of simulation tools. These 23 respondents were able to report on their use of 36 simulation tools. Multiple tools were reported, and were related to management education including for example, Adonis, ARIS, SimVenture and the Beer Game, Auditing Simulation, Business Simulation, Risk Manager Trading simulation, Simula, SimVenture.

The findings of this study reflect the claims in the literature for the need of non-traditional tools in management education. The reasons for using such simulations confirm what has been reported in the literature so far, such as the fact that the provision of visual or graphic demonstrations are easier to understand. Respondents highlighted the great impact on learner employability after using these tools, particularly in the cases where the tools used in education were the same as those used in business. Respondents explained that simulations placed students in real-life situations, helping them to learn by doing and from their mistakes. In fact, successful outcomes or right answers are not so important on their own, as is the whole "experience". Although most of these tools are expensive, they are cheaper than doing the "real thing". This hands-on approach gives students control of their learning (in class or outside class) and increases their feeling of achievement. In general, simulations require a (steep) learning curve for teachers and learners. Some software versions are complicated to install and use, including the configuration of starting conditions. This is why in some cases respondents preferred paper-based or board (i.e. physical, not computerized/virtual) versions.

Despite the need for such tools, respondents stressed the difficulties in getting access to simulation software. The reasons mentioned ranged from usability to cost. Respondents stated that academics that possessed technical capabilities were able to manufacture and/ or operate their simulations. However, the majority needed training, which sometimes is not available, time consuming or too expensive. Some of the most "desirable" simulation tools have high costs, even in educational versions - these tools are the most popular and widely used in academia. These tools include instruction 


\section{Ezz, Loureiro-Koechlin, and Stergioulas}

materials connecting them with management teaching content such as text books and journal papers. In addition, there are also license restrictions for some of these tools. Risk-averse people would rather use cheaper alternatives if they could find them (e.g., open source software, board/paper games.) None of the respondents was aware of open solutions such as open education resources (OER), although, as Johnstone (2005) stated, increasingly OER are these days becoming widely accessible across the globe with low and no cost, which has the potential to address the cost challenge reported above. The impact of open educational resource initiatives is potentially huge for learners, educators and educational institutions in the near future. As Johnstone (2005) clarifies, OER include:

- Learning resources - courseware, content modules, learning objects, learner-support and assessment tools, online learning communities

- Resources to support teachers - tools for teachers and support materials to enable them to create, adapt, and use OER, as well as training materials for teachers and other teaching tools

- Resources to assure the quality of education and educational practices.

\subsection{The OpenScout Portal: Provision of Open Simulations in the Management Field}

The OpenScout project (www.openscout.net) aims to encourage the use of Open Educational Resources (OER) in the management field. Knowledge and use of OER has grown in the last few years, but access to OER is not widely available yet. Most sources in Europe have developed OERs independently, with minimal interaction with stakeholders from other countries. Because of this, OER is still difficult to find. To improve this situation, the OpenScout project has built the OpenScout portal (http://learn.openscout.net), a federation of digital repositories of free, open management content. According to Sánchez-Alonso et al. (2011), learning object repositories (LOR) are digital collections of educational resources and/or metadata aimed at facilitating reuse of materials worldwide. In open repositories, resources are made available at no cost, representing a case of information sharing with an implicit and diffuse social context. Through OpenScout, users can easily access content held in repositories across Europe and beyond. OpenScout includes simulation content such as simulation games, serious games, MUD and Virtual Worlds.

The project constantly adds new resources from existing repositories in order to achieve significant coverage of the volume of open educational management content developed in Europe. However, their coverage of simulation-based content has been restricted by their limited availability. The OpenScout partners have learned from first-hand experience that unlike traditional OER (e.g., word documents, presentations, videos), open simulations are scarce and difficult to find. While nowadays the average teacher and the average learner are able to use and create word documents and spreadsheets, very few have experience in using simulations, let alone creating open simulations. This could be one of the reasons why such resources are not normally uploaded in open repositories (another reason being the use of non-open, not free simulations). This differs greatly with the significant amount of content that can be found about simulations. This can be easily verified in the OpenScout portal by comparing searches for simulation as a keyword and simulation, or games, etc. as type of content. The first search returns 10 times more resources than the second one (information obtained on 26/04/2012 from the Openscout portal). Figure 1 shows Sample screenshots from the OpenScout main page and one of its simulation games provided. 


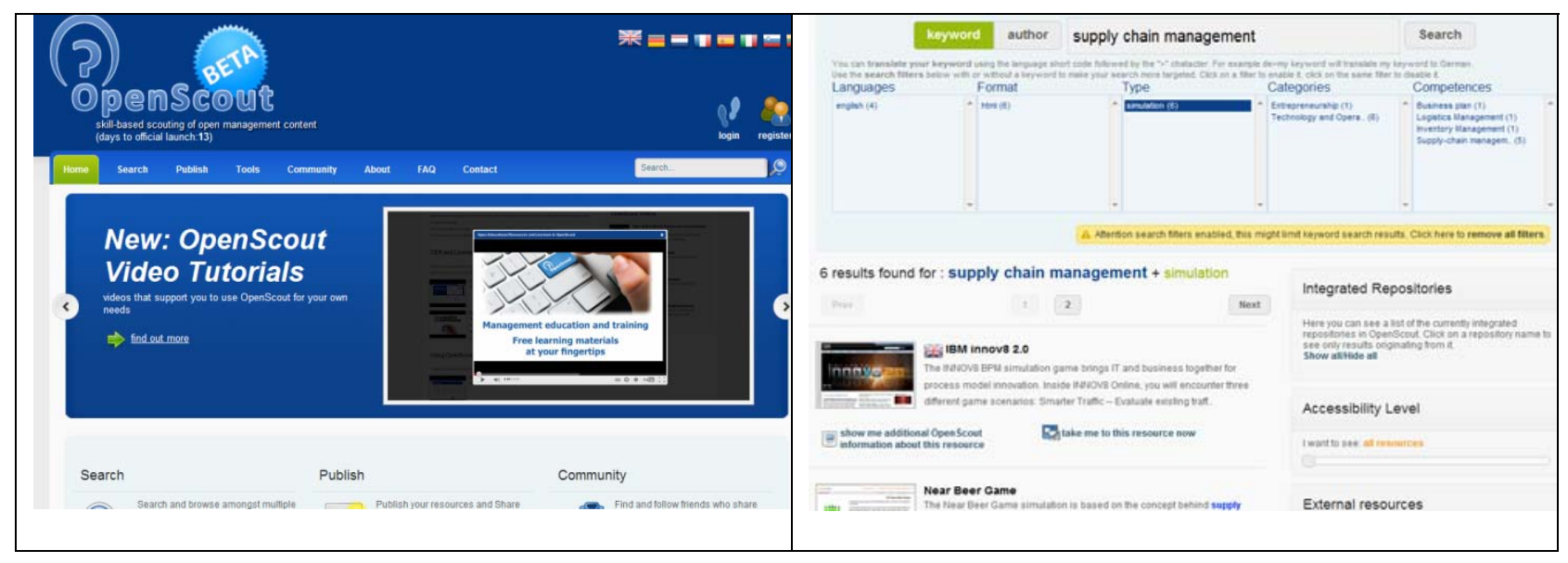

Figure 1: Sample OpenScout Screenshots

The lessons learned from the OpenScout experience show that there is much work to do to widely promote the use of open simulations in management education. The lack of content needs to be overcome, by encouraging users to create and share their simulations. However, at the same time, appropriate tools need to be created to facilitate their development. The creation of repositories like OpenScout should encourage people to pay more attention to this and to start creating, using and sharing simulations.

\section{CONCLUSION}

This paper discussed the use of simulation tools in the context of business education and managerial training. The reported results from our brief study on simulation tools confirm these needs. Respondents highlighted the great impact on employability in learners after using these tools. Respondents explained that simulations would place students in real-life situations, helping them to learn by doing and from their mistakes. An example of an open education outlet providing simulation content has been given by the OpenScout portal, which facilitates access to open educational resources (OER) in the area of management education and training. OpenScout has collected resources from multiple sources (mostly business schools) located in different European countries, and thus could also be considered as a learning object repository (LOR). Through OpenScout, users can easily access content held in repositories across Europe and beyond. OpenScout includes simulation content, such as simulation games, serious games, MUD and Virtual Worlds.

These initial experiences in collecting open simulation content demonstrate the limited availability of this kind of resources. The OpenScout experience shows that there is much work still to be done in order to widely promote the use of open simulations in management education. Simulations are a special kind of content, sharing many characteristics with software applications, rather than documents or spreadsheets. Because of this, special considerations (i.e., expertise, training) need to be taken into account to create, use and adapt them. It is particularly important to promote User Generated Content (UGC) among management academics and practitioners. This, we expect, will increase the availability and awareness of OER Simulations. Future research in this area might focus on creating frameworks and guidelines for quick and efficient development and distribution of simulations.

\section{ACKNOWLEDGMENTS:}

This research has been co-funded by the European Commission under the eContentplus Targeted Project OpenScout, grant ECP 2008 EDU 428016 (cf. http://www.openscout.net). 


\section{Ezz, Loureiro-Koechlin, and Stergioulas}

\section{REFERENCES}

Abt, C. C. 1970. Serious games. New York: Viking Press.

Ackermann, A. D. 2009. "Investigation of learning outcomes for the acquisition and retention of CPR knowledge and skills learned with the use of high-fidelity simulation." Clinical Simulation in Nursing 5: 213-222.

Adobor, H., \& Daneshfar, A. 2006. "Management simulations: determining their effectiveness." Journal of Management Development 25: 151-168.

Adobor, H., \& Daneshfar, A. 2006. "Management simulations: determining their effectiveness." Journal of Management Development 25: 151-168.

Alarcon, L. F., \& Ashely, D. B. 1999. "Playing games: Evaluating the impact of lean production strategies on project cost and schedule." In Proceedings of the 7th annual conference of the international group of lean construction, IGLC-7, 263-273.

Albrecht, W. D. 1995. "A financial accounting and investment simulation game." Issues in Accounting Education 10: 127-140.

Alinier, G. 2003. "Nursing students' and lecturers' perspectives of objective structured clinical examination incorporating simulation." Nurse Education Today 23: 419-426.

Anderson, E. G., Jr., \& Morrice, D. J. 2000. "A simulation game for teaching service-oriented supply chain management: Does information sharing help managers with service capacity decisions?" Production and Operations Management 9: 40-55.

Avolio, B. J. 1988. "Transformational leadership in a management game simulation." Group \& Organization Studies 13: 59-80.

Baker, A., Navarro, E. O., and van Der Hoek, A. 2005. "An experimental card game for teaching software engineering processes." Journal of Systems and Software 75: 3-16.

Barrese, J., Scordis, N., \& Schelhorn, C. 2003. "Teaching introductory concepts of insurance company management: a simulation game." Review of Business 24: 43-49.

Bruce, R. 2008. "Business simulator takes off." Financial Director16.

Cherry, R. A., Williams, J., George, J., and Ali, J. 2007. "The effectiveness of a human patient simulator in the ATLS shock skills station." Journal of Surgical Research 139: 229-235.

Chua, A. Y. K. 2005. "The design and implementation of a simulation game for teaching knowledge management. “ Journal of the American Society for Information Science and Technology 56: 12071216.

Chua, A. Y. K. 2005. "The design and implementation of a simulation game for teaching knowledge management." Journal of the American Society for Information Science and Technology 56: 12071216.

Clark, E. 2009. "Learning outcomes from business simulation exercises - challenges for the implementation of learning technologies." Education \&Training 51: 448-459.

Cook, R. W., \& Swift, C. O. 2006. "The pedagogical efficacy of a sales management simulation." Marketing Education Review 16: 37-46.

Cousens, A., Goffin, K., Mitchell, R., van der Hoven, C., and Szwejczewski, M. 2009. "Teaching new product development using the 'CityCar' simulation." Creativity and Innovation Management 18: $176-189$.

Cullingford, G., Mawdesley, M. J., \& Davies, P. 1979. "Some experiences with computer based games in civil engineering teaching." Computers \& Education 3: 159-164.

Curland, S. R., \& Fawcett, S. L. 2001. "Using simulation and gaming to develop financial skills in undergraduates. “ International Journal of Contemporary Hospitality Management 13: 116-119.

Ellington, H., Addinall, E., \& Percival, F. 1981. Games and simulations in science education. London: Kogan Page Limited.

Ellington, H., Addinall, E., and Percival, F. 1981. Games and simulations in science education. London: Kogan Page Limited. 


\section{Ezz, Loureiro-Koechlin, and Stergioulas}

Faria, A. J. 1998. "Business simulations games: current usage levels - an update.” Simulation Gaming 29: 295-308.

Faria, A. J., \& Wellington, W. J. 2004. "A survey of simulation game users, former-users, and neverusers." Simulation \& Gaming 35: 178-207.

Faria, A. J., and Dickinson, J. R. 1994. "Simulation gaming for sales management training." Journal of Management Development 13: 47-59.

Faria, A. J., Hutchison, D., Wellington, W. J., and Gold, S. 2009. "Developments in business gaming: a review of the past 40 years." Simulation Gaming 40: 464-487.

Gold, H., \& Gold, S. 2010. "Beat the market: an interactive microeconomics simulation." The Journal of Economic Education 41: 216.

Gosen, J., \& Washbush, J. 2004. "A review of scholarship on assessing experiential learning effectiveness." Simulation and Gaming 35: 270-293.

Hantsaridou, A. P., Theodorakakos, A. Th., and Polatoglou, H. M. 2005. "A didactic module for undertaking climate simulation experiments." European Journal of Physics 26: 727-735.

Holweg, M., \& Bicheno, J. 2002. "Supply chain simulation - a tool for education, enhancement and endeavor." International Journal of Production Economics 78: 163-175.

Holzinger, A., Kickmeier-Rust, M. D.,Wassertheurer, S., \& Hessinger, M. 2009. "Learning performance with interactive simulations in medical education: lessons learned from results of learning complex physiological models with the HAEMOdynamics SIMulator." Computers \& Education 52: 292-301.

Johnstone, S.M. 2005. "Open Educational Resources serve the world." Educause Quarterly 3: 15-8.

Khaled, N. 2001. "Managing construction equipment buy and sell decisions replacement: A simulation game." In ASC proceedings of the 37th annual conference, pp. 187-198.

Lane, D. C. 1995. "On a resurgence of management simulations and games." The Journal of the Operational Research Society 46: 604-625.

Larreche, J.C. 1987. "On Simulations in Business Education and Research.” J BUSN RES 15:559-571.

Leger, P.-M. 2006. "Using a simulation game approach to teach enterprise resource planning concepts." Journal of Information Systems Education 17 (4): 441-447.

Lewis, M. A., and Maylor, H. R. 2007. "Game playing and operations management education." International Journal of Production Economics 105: 134-149.

Liu, C.-C., and Kao, L.-C. 2007. "Do handheld devices facilitate face-to-face collaboration? Handheld devices with large shared display groupware to facilitate group interactions." Computer Assisted Learning 23: 285-299.

Looi, C.-K., Wong, L.-H., \& Song, Y. (in press). "Discovering mCSCL." In The International Handbook of Collaborative Learning., Edited by Hmelo-Silver, C., O’Donnell, A., Chan, C., and Chinn, C. New York: Routledge.

Mahboubian, M. 2010. "Educational aspects of business simulation softwares." Procedia Social and Behavioral Sciences 2: 5403-5407.

Margaret, M. 1995. "Industry simulation: A new type of business game tapping both analytic and synthetic skills." Training \& Management Development Methods 9: 627-639.

Mitchell, R.C. 2004, "Combining cases and computer simulations in strategic management courses." Journal of Education for Business 79 (4):198-204

Moratis, L., Hoff, J., \& Reul, B. 2006. "A dual challenge facing management education; simulation-based learning and learning about CSR.” Journal of Management Development 25: 213-231.

Nguyen, H. B., Daniel-Underwood, L., Van Ginkel, C., Wong, M., Lee, D., Lucas, A. S., et al. 2009. “An educational course including medical simulation for early goal-directed therapy and the severe sepsis resuscitation bundle: an evaluation for medical student training. "Resuscitation 80: 674-679.

Pasin, F. and Giroux, H. 2011. 'The impact of a simulation game on operations management education." Computers \& Education 57: 1240-1254.

Ponce, F. J. 2001. "Educational software tool based on a geographical information system (GIS) for radio wave propagation analysis." IEEE Transactions on Education 44: 355-363.

Prensky, M. 2003. "Digital game-based learning." Computer in Entertainment 1: 21. 


\section{Ezz, Loureiro-Koechlin, and Stergioulas}

Proserpio, L., and Gioia, D. A. 2007. "Teaching the virtual generation." Academy of Management Learning and Education 6: 69-80.

Qudrat-Ullah, H. 2010. "Perceptions of the effectiveness of system dynamics-based interactive learning. " Computers \& Education 55: 1277-1286.

Qudrat-Ullah, H., \& Karakul, M. 2007. "Decision making in interactive learning environments: towards an integrated model." Journal of Decision Systems 16: 79-99.

Randel, J. M., Morris, B. A., Wetzel, C. D., and Whitehill, B. V. 1992. "The effectiveness of games for educational purposes: A review of recent research." Simulation and Gaming 23: 261-276.

Romme, A. G. L. 2003. "Learning outcomes of microworlds for management education." Management Learning 34: 51-61.

Salas, E., Wildman, J. L., \& Piccolo, R. F. 2009. "Using simulation-based training to enhance management education." Academy of Management Learning and Education 8: 559-573.

Sánchez-Alonso, S, Sicilia. M., García-Barriocanal, E., Pagés-Arévalo, C., Lezcano, S. 2011. "Social models in open learning object repositories: A simulation approach for sustainable collections." Simulation Modelling Practice and Theory 19: 110-120.

Santos, J. 2002. "Development and implementing an internet-based financial system simulation game." Journal of Economic Education 33: 31-39.

Schwabe, G., amd Göth, C. 2005. "Mobile learning with a mobile game: Design and motivational effects." Journal of Computer Assisted Learning 21: 204-216.

Shapiro, S. J. 2003. “The marketplace game. “ Academy of Marketing Science Journal 31: 92-96.

Shifrony, E., \& Ginat, D. 1997. "Simulation game for teaching communication protocols." In Proceedings of the $28^{\text {th }}$ ACM computer science education symposium, SIGCSE, 184-188.

Siddiqui, A., Khan, M., Akhtar, S. 2008. "Supply chain simulator: A scenario-based educational tool to enhance student learning." Computers \& Education 51: 252-261.

Sparling, D. 2002. "Simulation and supply chains: Strategies for teaching supply chain management." Supply Chain Management 7:334-342.

Tao, Y., Cheng C., Sun, S. 2009. "What influences college students to continue using business simulation games? The Taiwan experience." Computers \& Education 53: 929-939.

Tao, Y., Cheng, C., \& Sun, S. 2009. "What influences college students to continue using business simulation games? The Taiwan experience." Computers \& Education 53: 929-939.

Terrell, S., \& Rendulic, P. 1996. "Using computer-managed instructional sSoftware to increase motivation and achievement in elementary school children." Journal of Research on Computing in Education 26: 403-414.

Uhles, N., Weimer-Elder, B., \& Lee, J. G. 2008. "Simulation game provides financial management training." Healthcare Financial Management 62: 82-89.

Van der Zee, D. J., and Slomp, J. 2009. "Simulation as a tool for gaming and training in operations managementda case study." Journal of Simulation 3: 17-28.

Vanhoucke, M., Vereecke, A., \& Gemmel, P. 2005. "The project scheduling game (PSG): simulating time/cost trade-offs in projects." Project Management Journal, 36: 51-60.

Weiss, S.S. 2008, "Mega-simulations in negotiation teaching: extraordinary investments with extraordinary benefits."Negotiation journal, 24 (3): 325-353.

Wells, R. A. 1993. "Management games and simulation in management development: an introduction." Journal of Management Development 9: 4-6.

Wolfe, J. 1993. "A history of business teaching games in English-speaking and post-socialist countries: the origination and diffusion of a management education and development technology." Simulation \& Gaming 24: 446-463.

Wonga, L., Boticki, I. Sun, J. Looi, C. 2011. "Improving the scaffolds of a mobile-assisted Chinese character forming game via a design-based research cycle." Computers in Human Behavior 27: 17831793.

Yin, C., Ogata, H., \& Yano, Y. 2007. "Participatory simulation framework to support learning computer science." Mobile Learning and Organisation 1: 288-304. 
Zurita, G., and Nussbaum, M. 2004. "Computer supported collaborative learning using wirelessly interconnected handheld computers. "Computers \& Education 42: 289-314.

\section{AUTHOR BIOGRAPHIES}

Inas Ezz received her $\mathrm{PhD}$ in Information Systems and Computing from Brunel University, UK. She is currently an Associate Professor of Information Systems and Computing, Sadat Academy for Management Sciences (SAMS), Egypt and a Visiting Fellow at the Department of Information Systems and Computing (DISC), Brunel University, UK. Further, she is a Part Time Lecturer at the German University in Cairo. Her research interests include systems integration in multiple aspects including but not limited to information management, business process reengineering, e-government, information systems adoption challenges, geographical information systems, and sustainable development. Her recent publications focus openness from different perspectives including innovation, and e-learning. In addition to other organizations she is also a member of the International Student Young Pugwash, and member of the Board of the Egyptian Pugwash (Pugwash Conferences on Science and World Affairs holding Nobel Prize since 1995).

Cecilia Loureiro-Koechlin is a Research Assistant at the School of Information Systems, Computing and Mathematics at Brunel University where she participates in large European funded projects in the area of Technology Enhanced Learning. Previously she has done research on social aspects of software development, eLearning \& eMentoring, semantic web, social software, online communities (of practice) $\&$ social networking sites. She is also interested in Structuration theory, qualitative data analysis, online research methods, online ethnography, language \& social interactions on the internet.

Lampros Stergioulas is Reader in the Department of Information Systems and Computing at Brunel University, UK. Dr Stergioulas has co-authored 4 books and published over 150 papers in journals and international conferences. He has been principal investigator and overall coordinator of numerous EU and UK projects. He has been an investigator in UK's RIGHT programme in healthcare simulation and modeling, and is currently coordinating the TEL-Map EU project on the Future of Technology Enhanced Learning. Dr Stergioulas has held many national and EU grants in information systems, healthcare systems management, modeling and simulation, educational information systems, digital literacy, Technology Roadmapping and human-centred computing. 